\title{
A força na incerteza: experimentos de reflexão crítica e de criação poética
}

\author{
Claudia Dias Sampaio
}

Pedrosa, Celia \& Alves, Ida (orgs.). Sobre poesia: outras vozes. Rio de Janeiro: 7 Letras, 2016.

A coletânea Sobre poesia: outras vozes, editada pela 7 Letras (2016), traz ao leitor textos de jovens escritores em seus experimentos de simultaneidade da escritura poética e ensaística.

O gesto de reunir, colocar em diálogo, é marca do trabalho das organizadoras - Celia Pedrosa e Ida Alves -, que vêm contribuindo para a reflexão sobre a poesia contemporânea no Brasil e em seus desdobramentos internacionais. Dessa parceria nasceram, por exemplo, Poesia contemporânea: voz, imagem, materialidades (UFMG, 2016); Subjetividades em devir: estudos de poesia moderna e contemporânea (7Letras, 2008) e Crítica de poesia: tendências e questões. Brasil-Portugal (7Letras, 2014), este último organizado com Nuno Judice como resultado de um projeto integrado de pesquisa e cooperação internacional entre instituições brasileiras e portuguesas. Sobre a poesia: outras vozes vem se somar, portanto, a essa trajetória produtiva e exitosa.

A proposta da antologia, segundo nos contam no texto de apresentação, é a de reunir jovens escritores dedicados ao exercício simultâneo da reflexão crítica e da criação poética, inscritos numa versão repaginada da noção tão cara à modernidade de "poetas-críticos", como aponta Marcos Siscar no posfácio. Aliás, o trabalho de Siscar é hoje imprescindível para os que se dedicam à pesquisa da poesia contemporânea. E a escolha dele para escrever o posfácio, assim como a do também poeta, crítico e professor Ítalo Moriconi, outra referência fundamental nessa área, para assinar a orelha do livro, é certamente mais um gesto significativo na reunião heterogênea que promovem as organizadoras.

Em sua reflexão sobre os ensaios e poemas que constituem o livro, ao qual se refere como "uma antologia experimental", Siscar aponta a presença de uma escrita associada à tradução, já que "traduzir é um modo de ensaiar": 
Note-se que há, em vários desses esforços de tradução, certa descontração, certa leveza na maneira como expõem seus limites e motivações, seus interesses e tarefas. A leveza não oferece garantias ao movimento que promete, mas de fato confirma o desejo de deslocamento de nossa relação com a norma, especificamente um desejo de alteração do tom dominante (de um tom "pesado", digamos) com que a discussão sobre poesia se colocou em épocas recentes.

A ideia de descontração e leveza se apresenta como potência e desejo de deslocamento da relação com a norma. Aqui, esse deslocamento nos chega através do uso da noção de "jocossério", desenvolvida por Adriano Scandolora; dos efeitos literários da relação entre pensamento e caminhada, como propõe a poeta portuguesa Golgona Anghel; da busca por uma fusão de tempos a partir da análise do anacronismo e da prosopopeia, por Leonardo Gandolfi. Assim, vai sendo apresentada ao leitor uma retomada diferenciada de procedimentos conhecidos.

Já o ensaio de Reuben da Rocha nos mostra cinco aspectos da poesia - em sua relação com mercado, oralidade, edição, prática pedagógica e estranhamento - pensados a partir da experimentação no atual contexto da arte e da discussão do híbrido e impuro contexto da vida literária. O da poeta argentina Nurit Kasztelan apresenta o trabalho do conterrâneo Mario Ortiz em seu Cuadernos de lengua y literatura. O procedimento de Ortiz de intercalar citações em grego com anedotas banais, num "equilíbrio justo entre alto e baixo", cria, segundo Nurit, um sistema de escritura que permite ao livro manter-se à margem da história, da economia e da própria poesia, mostrando assim a necessidade que esta tem de não se fechar em si mesma, mas sim a de reatualizar outros discursos, até mesmo o científico. O sujeito que desaparece no encadeamento entre citações gregas e anedotas banais nos Cuadernos de Ortiz também surge nos poemas de Nurit, dessa vez figurado numa dissolução que potencializa o modo de lidar com o próprio corpo. Assim lemos em "La molienda": "[...] En Méjico me contaron/ de una mujer/ a medida que molía el maíz/ su brazo iba desapareciendo./ Soy como esa mujer/ que se muele a sí misma/ me escribo/ y desaparezco". O modo de lidar com o próprio corpo aqui é dissolvê-lo na linguagem. "Moer a si mesmo" é encontrar na linguagem o lugar de dissolução e ao mesmo tempo de reconstrução do sujeito, porque, à medida que o corpo físico (o braço) vai desaparecendo, outro vai sendo construído: o corpo do poema.

Em sua apresentação de ícones da cultura pop, o poema da mexicana Maricela Guerrero também se conecta ao questionamento da forma de lidar com o corpo, 
apresentando uma vez mais a ideia de dissolução do sujeito: "[...] polvo seremos, $y$ a estas alturas, vaya a saber si polvo enamorado; quizá enormes pechos consagrados por el celuloide, los platillos/ mahlerianos, qué otra cosa/ el azúcar se disuelve/ te friega los dientes y las arterias [...]”. Os elementos do cotidiano - o açúcar, os pratos, o pó - estão conectados à dimensão da terra, trazida já no título (com a expressão horaciana "Beatus ille", que exalta a vida no campo); na referência a Mahler, que se desdobra em sua célebre Canção da terra; e nas imagens recorrentes de dissolução: "todo se combustiona, los cuerpos/ se corrompen, desaparecen". O que marca então o procedimento de Guerrero é o exercício do compêndio; no caso dos poemas são as tantas referências da cultura ocidental à dimensão da terra. Um procedimento de compilação também surge em seu ensaio, no qual a autora mexicana se dedica a pensar a relação que os poemas guardam com a linguagem cotidiana a partir da coleta de dados de redes sociais. O interesse de Guerrero por criar novos modos de categorizar através da linguagem aponta uma vez mais para o desejo de deslocamento da relação com a norma, conforme pensou Siscar, e indica sobretudo o reiterado questionamento sobre os modos de apresentação do sujeito na poesia contemporânea.

Tal discussão integra também a proposta de cruzamento entre poema e ensaio de Marília Garcia. Tanto "Plano B” quanto "O poema no tubo de ensaio" distendem a linguagem poética. “O ensaio é teste experimento prova." E o leitor não está a salvo das interrupções e frustrações próprias das experimentações. Um desses momentos é quando Marília cita “Um teste de poesia”, poema de Charles Bernstein, que ela promete ler e logo diz que desistiu, mas recomenda que o leitor não desista e leia a tradução de Haroldo de Campos a partir de um determinado link. Mais adiante ela justifica sua desistência por preferir ler um outro poema, ao qual se refere como "uma performance" - “O que faz um poema ser um poema?" -, indicando ao leitor mais um link, dessa vez um vídeo do Youtube no qual o próprio Bernstein a executa.

Assim vemos surgir a relação da poesia com as novas tecnologias: na possibilidade de recolher e recompilar dados de sites de busca e redes sociais (Maricela Guerrero) e pela conexão com links que levam a textos e vídeos (Marília Garcia), por exemplo. Nesse panorama de intertextualidades, onde o poema se relaciona com a internet, com a performance, a música, o cinema e o vídeo, o leitor vai conhecendo importantes referências contemporâneas, como a revista Modo de Usar, editada por Ricardo Domeneck, Marília Garcia e Angélica Freitas; e o cinema de Eduardo Coutinho, citado por Leonardo Gandolfi e por Lucas de Mello Cabral e Matos. 
Não à toa, porque os filmes de Coutinho embaralham a noção de gênero e têm por princípio o "gesto de fazer de sua arte uma escuta de corpos que falam", como observou Lucas.

Corpos que se reconfiguram na linguagem, cuja exegese é o corpo mesmo do poema, corpos que se oferecem à conexão com o leitor a partir da fragmentação dos órgãos que colocam em disputa os sentidos: é o que está presente em alguns dos textos que constituem o livro. Assim lemos, por exemplo, no ensaio de Ricardo Domeneck, "Juliana Krapp: as transações entre indivíduo e mundo através da pele e língua". Ao analisar um dos poemas de Krapp, "Limite", Domeneck chama a atenção do leitor para a dificuldade ao aproximar-se de um texto como esse, que "requer atenção avessa à pressa das atualizações de hoje, não por qualquer hermetismo, mas porque sua poesia parece tão clara naquilo que Jacques Roubaud definiria como o 'não parafraseável'”. O ensaísta confessa que sua vontade de exegese para um poema como esse resultaria em dizer ao leitor que a "exegese deste poema é o próprio poema". Para que tenhamos uma ideia do que provoca a inquietação de Domenek, destaco uma das estrofes de "Limite":

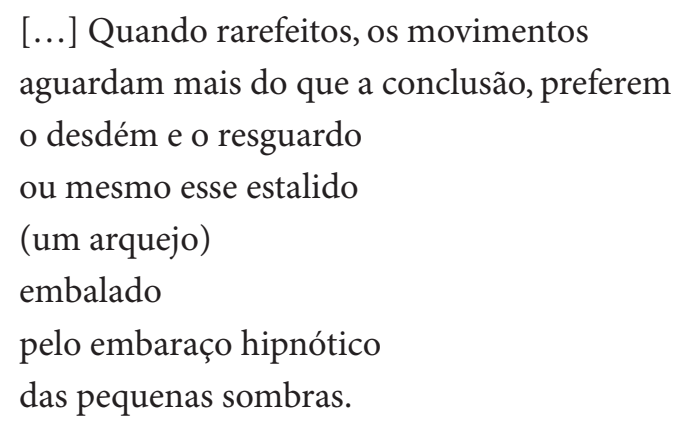

Imagem como essa, sutil, de um estalido "embalado pelo embaraço hipnótico de pequenas sombras", pode ser pensada como um dos momentos da leveza da qual nos fala Siscar. Mais próximos de uma leveza com certa descontração seriam momentos como o poema "Crocodilo", de Leonardo Gandolfi: "[...] Sempre me distraio/ com a contemplação dos meu próprios/ dias, diz o capitão, sempre me divirto/ com o desenrolar da vida dos outros". Outro momento é o poema de Lucas Matos: "Um juiz não sorri”: "[...] a bem da verdade achou divertido/ quando ao princípio da peça/ acusatória do promotor escutou/ três demonstrações bastante/ razoáveis da inexistência de Deus". 
Nesse contexto de descontrações, dissoluções e referências variadas - no qual repercute a indagação "o que faz um poema ser um poema?" -, vale a pena seguir a orientação de Siscar de transgredir a ordem proposta pela edição e ler o ensaio de cada autor seguido por seu respectivo poema. Desse modo o leitor poderá desfrutar com mais acuidade da reflexão proposta por cada um dos autores. Mas de ambos os modos Sobre a poesia: outras vozes aponta procedimentos de criação, reflexão e desautomatização da leitura altamente recomendáveis nos dias de hoje.

Claudia Dias Sampaio é Doutora em Letras pela Universidade Federal do Rio de Janeiro 